\title{
Escalas de medición de aculturación en estudiantes de Educación Superior
}

\section{Acculturation measurement scales in Higher Education students}

\author{
Sandy Martínez-Lara \\ Universidad Autónoma de Nuevo León, Monterrey, México \\ Oswaldo Leyva-Cordero
}

Universidad Autónoma de Nuevo León, Monterrey, México
Open Access:

ISSN: $0124-2121$

E-ISSN: 2665-2420

\section{Resumen}

Objetivo: Validar el instrumento de medición diseñado para evaluar los factores que facilitan el proceso de aculturación en estudiantes de Educación Superior durante su intercambio académico en el extranjero. Método: La investigación fue de carácter cuantitativa, utilizando pruebas estadísticas de fiabilidad Alfa de Cronbach, y análisis factorial por la medida de Kaiser-MeyerOlkin (KMO) de cada una de las variables de investigación; aplicando un total de 189 encuestas. Resultados: La variable adaptación cultural obtuvo valores aceptados en las pruebas realizadas $a=.754$ y $\mathrm{KMO}=.707$, demostrando la importancia del conocimiento previo referente a las costumbres, tradiciones y estilos de vida del país, asimismo, la variable características de la institución mostró resultados satisfactorios, en donde $a=.813$ y $\mathrm{KMO}=.679$, probando la importancia de la estructura institucional, académica y estilos de aprendizaje de la institución receptora. Discusión y Conclusiones: El instrumento de medición aprobó de manera satisfactoria las pruebas estadísticas utilizadas dentro del proceso de validación, mismo que sirve como una herramienta para establecer modelos de adaptación cultural.

Palabras clave: Aculturación, adaptación cultural, intercambio académico.

\section{Abstract}

Objective: To validate the measurement instrument designed to evaluate the factors that facilitate acculturation process in Higher Education students during their academic exchange abroad programs. Method: The research was quantitative using statistical test of Cronbach's alpha reliability and factorial analysis integrated by the Kaiser-Meyer-Olkin (KMO) measure of each of the research variables. A total of 189 surveys were conducted. Results: The cultural adaptation variable obtained accepted values, where $\mathrm{a}=.754$ and $\mathrm{KMO}=.707$, demonstrating the importance of the impact on prior knowledge regarding the customs, traditions and lifestyle of the country. The institutional characteristics variable showed satisfactory results where $a=$ .813 and $\mathrm{KMO}=.679$, proving the importance of the institutional and academic structure and learning styles of the host institution. Discussion and Conclusion: The measurement tool satisfactorily approved the statistical test used within the validation process of a measurement instrument, which is used as a tool to establish models of cultural adaptation.

Keywords: Acculturation, cultural adaptation, academic exchange.

\section{ARTÍCULO DE INVESTIGACIÓN CIENTÍFICA
Copyright $@ ~$ By Educación y Humanismo \\ Editor: \\ Dhayana Fernández Matos}

Correspondencia: Sandy.martinezlr@uanl.edu. $\mathrm{mx}$
Recibido: $11-01-2021$ Aceptado: 28-04-2021 En línea desde: $25-08-2021$

Cómo citar este artículo (APA): Martínez-Lara, S. y Leyva-Cordero, O. (2021). Escalas de medición de aculturación en estudiantes de Educación Superior. Educación y Humanismo, 23(41), 138-163. https://doi.org/10.17081/eduhum.23.41.4831 


\section{Introducción}

La aculturación es un proceso que presentan los individuos al entrar en contacto con una cultura diferente a la suya (Ferrer et al., 2014). Sin embargo, existe una serie de diferentes definiciones, siendo una de las más importantes la propuesta por Folivoc (2009) quien define a la aculturación como el acercamiento que tienen los individuos con una cultura donde sus creencias, valores, tradiciones y prácticas son únicas y son aceptadas por un grupo de personas. Dando como resultado, habilidades sociales y de superación para poder así incorporarse de manera satisfactoria a una nueva cultura (Padoan, 2017).

Por otra parte, los estudios sobre aculturación han determinado diversos problemas que sufren los individuos al entrar en contacto con una cultura nueva. Es decir, existen múltiples factores externos como lo son: la relación con la gente, el contexto de la cultura, las actitudes de tiempo, los elementos distintivos y la disponibilidad de información. Así como también, factores de carácter interno de los individuos como: las estrategias de aculturación, el estrés por aculturación y el choque cultural (Oses, 2014).

Asimismo, los estudios sobre aculturación destacan los enfoques de metodología cualitativa en oposición a los enfoques cuantitativos (Arenas y Urzúa, 2016). Sin embargo, Borboa y Delhumeau (2016) presentan las ciertas ventajas de utilizar metodología cuantitativa en este tipo de estudios, siendo las más sobresalientes el alto nivel de exactitud de los resultados y la comparabilidad de estos. Por otra parte, los métodos cuantitativos cuentan con la característica de ser precisos en los procesos de medición que se utilizan, dando como resultados de validez interna y externa del instrumento, los cuales contribuyen a presentar resultados de calidad de investigación (Cadena et al., 2017).

Por todo ello, el objetivo de esta investigación es construir un instrumento con validez y confiabilidad sobre los factores que facilitan el proceso de aculturación de los estudiantes de educación superior durante su intercambio académico al extranjero tomando como referencia los instrumentos propuestos por Oses (2014) y Peralta, Ramírez y Castaño (2006), esto debido al impacto y calidad de los datos que se han obtenido en diversas pruebas realizadas para medir el nivel de aculturación de los migrantes.

La metodología utilizada para esta investigación es de carácter cuantitativo en donde se utilizan pruebas estadísticas de fiabilidad Alfa de Cronbach, y un análisis factorial integrado por la medida de Kaiser-Meyer-Olkin (KMO) y Bartlett, la prueba de índice de adecuación a la muestra individual, comunalidades y la varianza total explicada de cada una de las variables de investigación; las cuales son: adaptación cultural, contexto de la cultura, características de la institución, resiliencia y relación con la gente. 
Dentro de los principales resultados fue encontrado que la variable adaptación cultural cuenta con valores aceptados en todas las pruebas demostrando la importancia del impacto en los estudiantes sobre el conocimiento de las costumbres, tradiciones y estilos de vida del país donde realizarán la movilidad académica, así como el contexto de la cultura, las características de la institución, resiliencia y relación con la gente.

En conclusión, el instrumento de medición aprobó de manera satisfactoria las pruebas estadísticas utilizadas dentro del proceso de validación de un instrumento de medición, mismo que sirve como una herramienta para futuras investigaciones referentes a la línea de investigación. Asimismo, el instrumento utilizado en esta investigación es complemento de instrumento publicado de Oses (2014) debido al impacto y similitud de la muestra, es decir, instrumentos utilizados en estudiantes que realizan una movilidad académica. Por tal motivo, el instrumento presentado en esta investigación cuenta con la ventaja de adecuación y confiabilidad para el proceso de adaptación cultural durante una movilidad académica.

\section{Aculturación en el contexto educativo}

A lo largo de la historia, el contacto entre individuos de diversas culturas resulta ser cada vez más común y frecuente. Tanto que, las personas nacidas en una cultura a menudo buscan visitar sociedades diferentes a las suyas con el fin de trabajar, estudiar o ejercer algún tipo de influencia en el país extranjero (Ward, Bochner y Furnam, 2001).

En los últimos años, el fenómeno de la globalización trae como consecuencia que el contacto entre personas de diferentes contextos culturales este en aumento. Como consecuencia a esto, resulta que exista un mayor intercambio de ideas entre diferentes culturas, pero a su vez, ocasiona una molestia entre los participantes debido a los contrastantes cambios de valores, costumbres y prácticas sociales (Pozzo, 2012).

Ante esto, el autor Church (1982) es uno de los primeros investigadores que realiza estudios sobre inmigrantes y estudiantes extranjeros. Al mismo tiempo, el autor demuestra que los estudiantes al llegar a una nueva sociedad manifiestan sentimientos de optimismo y entusiasmo. Sin embargo, estos sentimientos son sustituidos por estrés y ansiedad. En gran parte, debido a los problemas que enfrentan los estudiantes día a día que incluyen aspectos como la ubicación, el traslado, el dinero y un ambiente poco familiar. No obstante, una vez que los estudiantes logran superar estos problemas, logran alcanzar nuevamente los sentimientos de seguridad y bienestar en el entorno que se están desenvolviendo.

Posteriormente, Searle (1990) en su investigación expone que la cultura de procedencia de los estudiantes es un gran determinante para medir el grado de choque cultural que puedan presentar. Dicho en otras palabras, la cercanía cultural determina un menor esfuerzo de adaptación en comparación con aquellos estudiantes que provienen de una cultura más lejana. Por un lado, esto produce que los estudiantes lleven una mejor comunicación y los niveles de ansiedad, incertidumbre y estrés sean bajos o casi nulos. Mientras que, por otro 
lado, aquellos estudiantes que provengan de una cultura más lejana o con mayor distancia cultural, tendrán que esforzarse más para desarrollar las habilidades de comunicación y adaptación y poder así, presentar un buen desempeño en el país de visita (Lupano y Castro, 2013).

Por su parte, Berry, Phinney, Sam y Vedder (2006) muestra los resultados de un estudio realizado a estudiantes de universidad, en donde, las personas que mayor índice de discriminación referente a temas étnicos o culturales resultan ser, aquellos estudiantes inmigrantes que se encuentran de movilidad. Por lo tanto, los estudiantes que presentaron índices de discriminación presentaron una actitud de aislamiento.

Hechas las consideraciones anteriores, es importante mencionar la teoría del aprendizaje cultural. Asimismo, la teoría del aprendizaje cultural demuestra que todos los estudiantes que realizan una movilidad en el extranjero son integrados en tres principales grupos sociales, con la finalidad de evitar presentar índices de discriminación. Dichos grupos son:

1) Compatriotas: este grupo es el principal debido a que su función es brindar apoyo emocional a aquellos estudiantes que presenten algún tipo de choque cultural. Así como también reforzar la identidad y valores de la cultura de origen.

2) Cultura huésped: este grupo busca facilitar el apoyo para el cumplimiento de las labores académicos y profesionales que los estudiantes deben realizar durante su estancia en el extranjero.

3) Estudiantes internacionales: en este grupo están integrados aquellos estudiantes que son provenientes de una cultura diferente a la del país receptor. Es decir, su función es crear un apoyo entre estudiantes extranjeros (Tomasello, Kruger y Ratner, 1993).

Por lo dicho, la teoría del aprendizaje cultural demuestra que es común que los estudiantes estén integrados en algunos de estos grupos sociales. Sin embargo, es necesario comentar que no es de carácter obligatorio que los estudiantes extranjeros deban pertenecer a estos grupos. Es decir, existen estudiantes que no están relacionados con estos grupos y logran sobrevivir y adaptarse a la nueva cultura dejando atrás los sentimientos de aislamiento, estrés y choque cultural.

A lo largo de los planteamientos hechos, es oportuno mencionar a Castro (2011) en su investigación realiza un análisis de la forma en que los inmigrantes extranjeros realizan el proceso de adaptación también conocido como proceso de aculturación. En atención a, que los estudiantes tienen preferencias en las estrategias de aculturación. Dicho de otra forma, los estudiantes eligen la estrategia que mejor le convenga. Por lo tanto, el grado de éxito de los estudiantes en cuanto a la adaptación depende de la estrategia que seleccionaron para poder adaptarse. Específicamente, los estudiantes de Educación Superior vienen de un proceso de adaptación de manera temporal, es decir, de acuerdo con la duración de su 
movilidad, sin embargo, es importante que el estudiante conozca acerca del contexto cultural y logré poder interactuar con los locales. En tal sentido, los estudiantes en su mayoría eligen la integración como una estrategia exitosa para adaptarse mejor a la cultura receptora sin necesidad de perder los rasgos de la cultura original.

Por su parte, Fiocchi y Rojas (2015) afirman que todos los programas de intercambio aportan al estudiante internacional una serie de efectos positivo y que son descritos a continuación: a) mayor valoración de la diversidad cultural, b) aumento de la confianza en sí mismo en cada uno de los estudiantes, c) desarrollo de pensamiento propio e independencia, d) adquisición de habilidades de comunicación e interacción social y finalmente, e) lograr una mayor capacidad adaptativa frente a problemas y desafíos.

De los anteriores planteamientos se deduce que, en la actualidad, es evidente que la internacionalización de la educación superior, a través de los programas de intercambio y movilidad académica es cada vez más común y son muchos los estudiantes que buscan vivir esta experiencia. Significa entonces que, los estudiantes buscan la forma de poder realizar una movilidad en un país extranjero con la finalidad de adquirir nuevos conocimientos y habilidades tales como: práctica de un segundo idioma, experiencia profesional con valor curricular en el extranjero, independencia, y seguridad. Asimismo, se busca que los estudiantes logren adquirir nuevos conocimientos y amplíen su visión global el cual le ayude en su desarrollo y desempeño profesional.

\section{La medición de la aculturación}

El fenómeno psicológico primordial que tiene que enfrentar un estudiante extranjero se denomina aculturación y es el proceso de cambio psicológico y cultural resultado del contacto intercultural (Berry et al., 2006). Los cambios culturales incluyen alteraciones en las costumbres y en la vida económica y política de los grupos en contacto. Los cambios psicológicos (aculturación psicológica) involucran variaciones en las actitudes hacia el proceso de aculturación, la propia identidad y las conductas hacia la cultura huésped.

La adaptación puede ser psicológica o cultural. La adaptación cultural involucra la puesta en marcha de habilidades sociales necesarias para funcionar adecuadamente en un entorno cultural complejo (Ward et al., 2001).

Debido a esto es ahora muy común que los migrantes sufran ahora por las características de estrés aculturativo si la adaptación no se alcanza de una forma favorable. Esto ocurre cuando las personas experimentan reacciones físicas y emocionales adversas como resultado del complejo ajuste que deben realizar en un contexto cultural poco familiar. El estrés aculturativo surge de la tensión experimentada al contrastar los valores y costumbres

de la cultura propia en un contexto cultural de la cultura propia en un contexto cultural 
diferente (Castro, 2011).

Aquellos migrantes que manejan mejor el estrés son los que tienen una mayor competencia intercultural. Este concepto es relativamente nuevo y comprende la autoconciencia de los propios valores culturales, el conocimiento de aquellos que tienen valores culturales opuestos o diferentes a los propios y la adaptación de las propias conductas a las necesidades de los grupos culturalmente diversos (Ang, et al., 2004)

De acuerdo con la investigación realizada por, Oses (2014) existen diversos instrumentos que miden la aculturación. Como resultado, fueron identificados instrumentos con un enfoque metodológico cualitativo y cuantitativo. De los cuales en su mayoría miden la aculturación a través del nivel de adaptación cultural que presentan los individuos (Paz, 2017). Sin embargo, Berry et al., (2006) señala que la aculturación puede medirse utilizando instrumentos estandarizados con base a diversas dimensiones. Dicho de otra manera, la aculturación es apta para utilizar instrumentos que engloben diversos enfoques de acuerdo con el propósito con el que fue creado.

Si bien es cierto que, la medición de la aculturación ha sido analizada por investigaciones en diferentes países, con diversos sujetos de estudios y enfoques múltiples, como lo muestran los estudios de Navas et al., (2004), Hendrix (2015), Minjárez (2012) y Castro (2011), entre otros. Al mismo tiempo, entre de los estudios más destacados en el tema de aculturación es el realizado por Ryeder et al., (2000) y Berry et al., (2006) debido a la relación entre aculturación y el dominio general de las costumbres de los individuos. Como resultado de esto, el instrumento conocido por su título traducido al español cuestionario del ámbito de aculturación es el detonante para realizar abundantes investigaciones, entre ellas Arends-Tóth y Van de Vijer, (2007), Páez et al., (2000) y Bartolomé et al., (2005), Oses (2004) y Peralta, Ramírez y Castaño (2006). Así como también, otros estudios donde este mismo instrumento ha sido aplicado y validado, de los cuales destacan Granada (2003), Guzman y Burke (2003), Hernández et al., (2011) y Jiménez (2015).

Para el caso específico del desarrollo de investigaciones sobre aculturación en el contexto educativo Beaven (2012) presenta un análisis sobre la importancia de la comprensión de la aculturación con base en las siguientes características: perfil del estudiante, ocupación, país receptor y cultura receptora. Es decir, la aculturación en el contexto educativo implica el análisis de características que van más allá de la cultura del país donde los estudiantes realizarán la movilidad académica.

El instrumento cuestionario del ámbito de aculturación utilizado por Oses (2014) y Peralta, Ramírez y Castaño (2006) consiste en un total de 12 dimensiones integradas por 128 ítems distribuidos en cada una de las mismas. La primera de ellas recoge la información sobre la relación con la gente integrada por subdimensiones como lo son el individualismo versus colectivismo, control de la incertidumbre, universalismo versus particularismo, masculinidad versus femineidad, orientación a corto plazo versus orientación a largo plazo, 
por mencionar alguna. Sin embargo, parten el instrumento en la perspectiva del estudiante antes de realizar la movilidad y la realidad que vive el estudiante durante su movilidad. Dando como resultado las 12 dimensiones del instrumento. Igualmente, el instrumento utiliza una escala Likert de 5 niveles.

\section{Método}

La metodología cuantitativa utilizada en esta investigación quedó integrada por tres fases. La primera fase corresponde a la pertinencia de las variables. Es decir, la validación de pertinencia por parte de los expertos entrevistados, con la finalidad de definir las variables con mayor grado de importancia. Ante esto, los expertos fueron 13 profesores investigadores vinculados a las áreas de métodos de investigación cuantitativa, análisis de datos, depuración de bases de datos e internacionalización de la Educación Superior.

Posteriormente, la fase dos, corresponde a la elaboración del instrumento piloto, integrado por: la aproximación teórica, la creación de base de datos, validez de contenido, delimitación de estudio, determinar la población, realizar el cálculo de la muestra y definir el perfil de los encuestados. Finalmente, la fase tres, estuvo integrada por el proceso de recolección de datos, análisis de fiabilidad y el análisis factorial de los datos a través del programa estadístico IMB SPSS V20. De acuerdo con, García et al. (2017) indica que el éxito del instrumento se enfoca en la calidad de resultados dentro de las pruebas estadísticas realizadas y la correcta depuración de la información.

La búsqueda de literatura estuvo enfocada en aquellas investigaciones donde el tema principal fuera aculturación, resiliencia, e instituciones universitarias extranjeras, y adaptación cultural, con la finalidad de identificar documentos que ayudarán a la elaboración del instrumento de medición. Los resultados arrojaron un total de 28 investigaciones sobre el proceso de aculturación, 32 investigaciones que utilizaron instrumentos para medir el proceso de aculturación en cinco dimensiones, tales como: adaptación cultural, contexto de la cultura, relación con la gente, características de la institución y resiliencia; tal como lo establece Aguilar et al. (2019), García et al. (2016), González et al. (2018), y Granados et al., (2017) para medir la resiliencia.

Una vez identificado que los instrumentos propuestos por Oses (2014) y Peralta, Ramírez y Castaño (2006) eran los instrumentos idóneos se adaptaron los ítems para esta investigación, a través del proceso de validez de contenido. Esto gracias a la estructura de medición, es decir, la manera clara en que se evalúan los diversos factores que integran el proceso de aculturación y su relación con los estudiantes que realizan una movilidad académica al extranjero.

En relación con lo anterior, el estudio para la validez de contenido fue enviado a 13 
expertos en temas de aculturación movilidad académica y adaptación cultural, así como profesores investigadores vinculados a las áreas de métodos de investigación cuantitativa, análisis de datos, depuración de bases de datos e internacionalización de la Educación Superior.

Asimismo, se envió de manera electrónica un listado de ítems propuestos con la finalidad de clasificar, ubicar y determinar el grado de relevancia de los ítems en un constructo, a través de la creación de un instrumento simple con una escala de medición de Likert de 1 a 5, donde 1 es nada pertinente y 5 altamente pertinente (Escobar et alı, 2008). En tal sentido, los resultados obtenidos por parte de los expertos fueron analizados mediante el proceso de selección de aquellas variables que tuvieran más de tres calificaciones iguales dentro del rango de escala altamente pertinente (5) e pertinente (4). Como resultado del instrumento de validez de contenido, los expertos propusieron un cambio en la redacción de ciertos ítems para lograr una mejor comprensión (Ver tabla 1).

Por otra parte, es importante mencionar que el objeto de estudio son los estudiantes de Educación Superior debido a que se busca incrementar la bibliografía existente en temas de aculturación en estudiantes, así como establecer un modelos de medición que sirve como base para establecer una serie de recomendaciones a seguir sobre el proceso de adaptación cultural, con la finalidad de brindar una mejor asesoría sobre las posibles problemáticas que se puede enfrentar un estudiante al momento de entrar en contacto con una cultura diferente.

Sin embargo, existen diversas formas de medir la aculturación tales como los instrumentos presentado por los autores presentados con anterioridad. No obstante, este instrumento está enfocado en medir la aculturación a través del proceso de adaptación cultural en estudiantes de Educación Superior que realizan una movilidad académica en el extranjero, tomando en cuenta factores de interacción directa con la cultura e institución receptora, habilidades sociales y capacidades de adaptación.

\begin{tabular}{ll}
$\begin{array}{l}\text { Tabla 1. } \\
\text { Ítems propuestos }\end{array}$ \\
\hline \multicolumn{1}{c}{ Variable } & \multicolumn{1}{c}{ Ítem propuesto } \\
\hline Adaptación cultural & 1. Conocimiento de la cultura receptora. \\
2. Identificarse con la cultura receptora. & 3. Integración \\
4. Seguridad en las relaciones interpersonales. \\
5. Ser sociable. \\
6. Aprendizaje de una cultura nueva. \\
7. Distancia cultural. \\
8. Participar en actividades de ocio de la cultura receptora. \\
9. Amistades en el país receptor. \\
10. Nivel de expectativa. \\
11. Clima del país receptor \\
12. Similitud entre las estructuras familiares \\
13. Religión del país receptor \\
14. Cultura receptora sociable \\
15. Medios de transporte \\
16. Gastronomía del país receptor \\
17. Sentirse a gusto con la cultural receptora
\end{tabular}




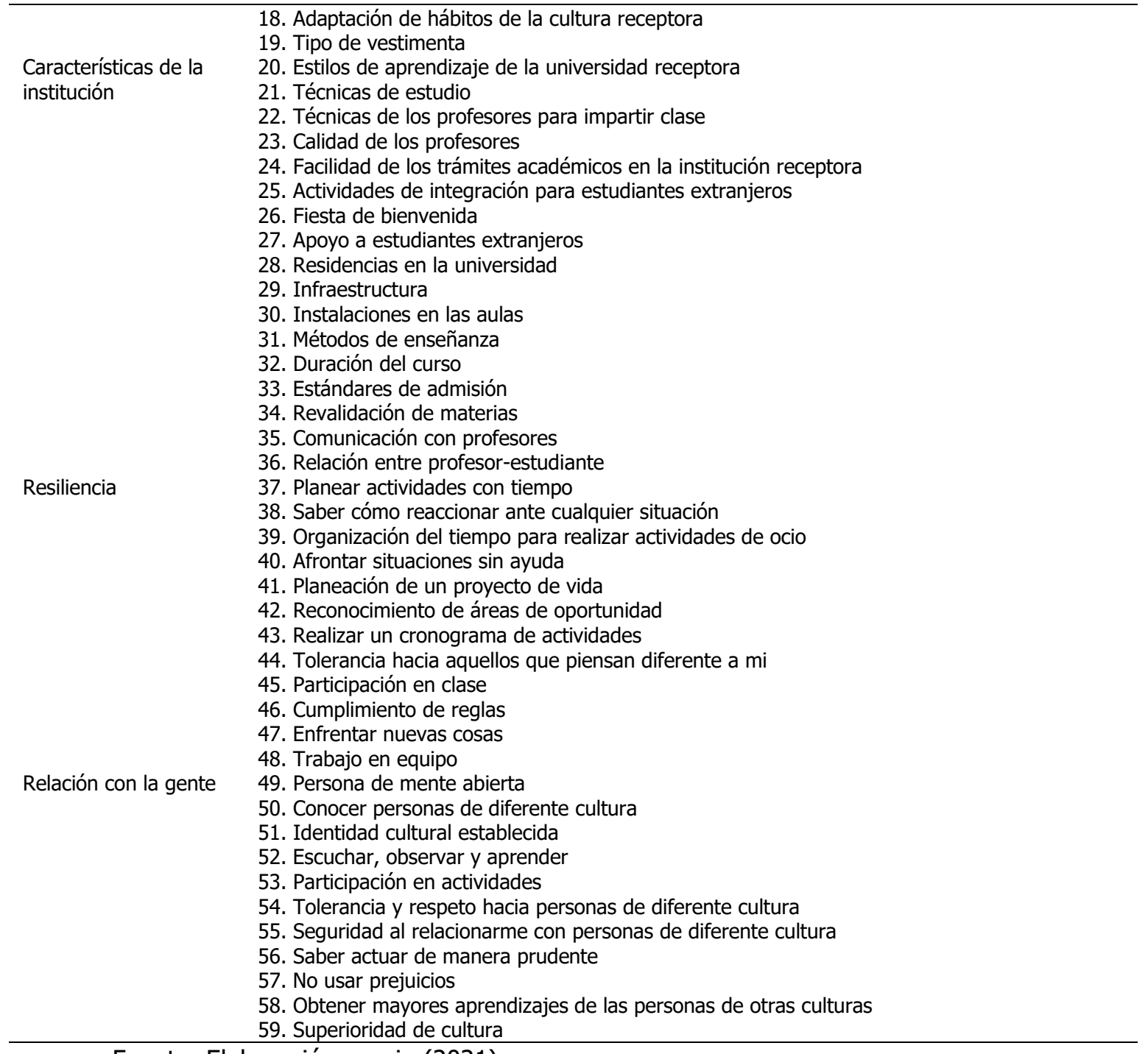

Fuente: Elaboración propia (2021)

Posteriormente, fueron agregados una serie de ítems de control que recogían información personal, nivel de estudios, facultad de procedencia y periodo del intercambio. Seguidamente, tras obtener los resultados de la aplicación del instrumento de medición los datos fueron sometidos a pruebas de fiabilidad, validez y la técnica exploratoria de reducción de dimensiones. Con el objeto de identificar y reducir los ítems que brinden poca información para el estudio. Para la realización de los análisis mencionados se ha utilizado el programa IBM SPSS 2019 versión V20.

\section{Instrumento Final}

El instrumento quedó conformado por cinco dimensiones, donde la dimensión uno cuenta 
con un total de 10 ítems. Posteriormente, la dimensión dos está integrada por 09 ítems. Seguidamente, la tercera dimensión la crean 17 ítems. Para continuar, con la cuarta dimensión conformada por 12 ítems. Finalmente, la quinta dimensión la integran 11 ítems, llegando a un total de 59 ítems. El instrumento es respondido por los participantes mediante una escala Likert de 5 niveles (donde $1=$ nada de acuerdo, 2= poco de acuerdo, 3= algo de acuerdo, 4= de acuerdo, 5= totalmente de acuerdo). De acuerdo con, González et al. (2018) indica que la escala Likert tiene la función de ordenar por grado de importancia las respuestas que integran un instrumento de medición, asimismo, los encuestan especifican el nivel de aceptación o grado de satisfacción que presentan ante una cuestión.

\section{Participantes}

La población objetivo de esta investigación son los estudiantes internacionales debido a que es un amplio grupo de personas que entra en contacto con una nueva cultura y es capaz de adquirir de entender la diversidad, respetar las diferencias culturales y cooperar con personas que son provenientes de una cultura distinta a la propia; lo que enriquece su experiencia y conocimientos sobre los procesos de adaptación cultural.

Ante esto, la aplicación del instrumento piloto de medición fue realizado a través del cálculo de la muestra, la cual quedó integrada por el total de estudiantes que realizaron un intercambio académico durante el 2016 al 2018. Adicionalmente, el muestro probabilístico simple fue seleccionado para especificar el tamaño de la muestra dado que los estudiantes debían de cumplir con ciertos requisitos predeterminados (García et al., 2006). Primeramente, que fueran alumnos inscritos a la Universidad Autónoma de Nuevo León. Seguidamente, que hayan realizado un intercambio académico al extranjero durante el periodo 2016 al 2018, esto debido a que durante este periodo se presentó un incremento de estudiantes de movilidad académica, gracias a los programas de vinculación con el sector público y privado. Al mismo tiempo, que los trámites académicos fueran gestionados por el Departamento de Intercambio Académico de la Universidad Autónoma de Nuevo León. Finalmente, participaron 189 alumnos. La tabla 2 muestra la descripción de la muestra.

\section{Tabla 2.}

\section{Variables de control del instrumento piloto}

\begin{tabular}{llcc}
\hline & & Frecuencia & Porcentaje \\
\hline Género & & 56 & $39 \%$ \\
& Masculino & 89 & $61 \%$ \\
& Femenino & & \\
& & 137 & $94 \%$ \\
& 20 a 25 años & 6 & $4 \%$ \\
& 26 a 30 años & 2 & $1 \%$ \\
Facultad & 31 a 35 años & & $14 \%$ \\
& FIME & 21 & $12 \%$ \\
& FAPSI & 17 & $11 \%$ \\
& FCPYRI & 16 & $10 \%$ \\
& FARQ & 15 & $9 \%$ \\
& FACPYA & 13 & $8 \%$ \\
& FCQ & 11 & $36 \%$ \\
\hline \multirow{6}{*}{ País } & OTRAS & 52 & \\
\hline
\end{tabular}




\begin{tabular}{lcc}
\hline España & 71 & $49 \%$ \\
Francia & 16 & $11 \%$ \\
Alemania & 16 & $11 \%$ \\
Chile & 11 & $8 \%$ \\
Otros & 31 & $21 \%$ \\
\hline
\end{tabular}

Fuente: Elaboración propia (2021)

\section{Resultados}

A continuación, se presentan los resultados de investigación:

\section{Prueba de Fiabilidad}

Para determinar la fiabilidad del instrumento fue utilizado el coeficiente de consistencia interna alfa de Cronbach. De acuerdo con, Cohen y Swerdlik (2001) afirman que el coeficiente alfa mide la exactitud de un instrumento para medir lo que necesita medir. Es decir, permite determinar el grado en que están relacionados los ítems. Para esta investigación el coeficiente fue obtenido por cada una de las dimensiones de estudio. La tabla dos muestra los valores del alfa de Cronbach para las cinco dimensiones de estudio, donde indican una alta consistencia. En un primer análisis fueron eliminados 4 ítems que no cumplían con los valores aceptables. Se realizarón pruebas posteriores con la finalidad de eliminar los ítems que sus valores estuvieran por debajo de .07. En total, fueron eliminados 20 ítems. Finalmente, se obtuvo un instrumento con la fiabilidad aceptada esto gracias a que todos sus valores oscilan entre 0.70 y 0.80 , por lo que se cuenta con un instrumento extremadamente fiable. La tabla 3 muestra los resultados de la prueba de fiabilidad Alfa de Cronbach.

\section{Tabla 3.}

Valores de Alfa de Cronbach

\begin{tabular}{lccc}
\hline \multicolumn{1}{c}{ Dimensión } & $\begin{array}{c}\text { Estadística de fiabilidad Alfa de } \\
\text { Cronbach }\end{array}$ & Elementos & Fiabilidad \\
\hline Adaptación cultural & .754 & 10 & Aceptada \\
Contexto de la cultura & .789 & 10 & Aceptada \\
Características de la institución & .813 & 16 & Aceptada \\
Resiliencia & .782 & 12 & Aceptada \\
Relación con la gente & .715 & 12 & Aceptada \\
\hline
\end{tabular}

Fuente: Elaboración propia datos obtenidos de IBM SPSS (2021) 


\section{Validez}

Posteriormente, para apoyar la validez del instrumento fueron realizadas las pruebas de Kaiser Meyer Olkin (KMO) y Bartlett. De acuerdo con, Méndez y Rondón (2012) aseguran que las pruebas de KMO y Bartlett miden la relación que existe entre dos variables o en su caso dos o más ítems. Al mismo tiempo, dicha prueba presenta el tamaño de las correlaciones entre las variables o ítems medidos. Autores como, Hair, et. al. (2005), Costello y Osborne (2005), Ferrando y Aguiano-Carrasco (2010) y Lévy y Varela (2003) afirman que los valores satisfactorios para el índice de KMO van entre 0.60 y 0.79 . Mientras que, los valores entre 0.80 y 1 son considerados como excelentes. La tabla cuatro muestra los valores de las pruebas de KMO y Barlett de las dimensiones de estudio.

Tabla 4.

Valores KMO y Barlett

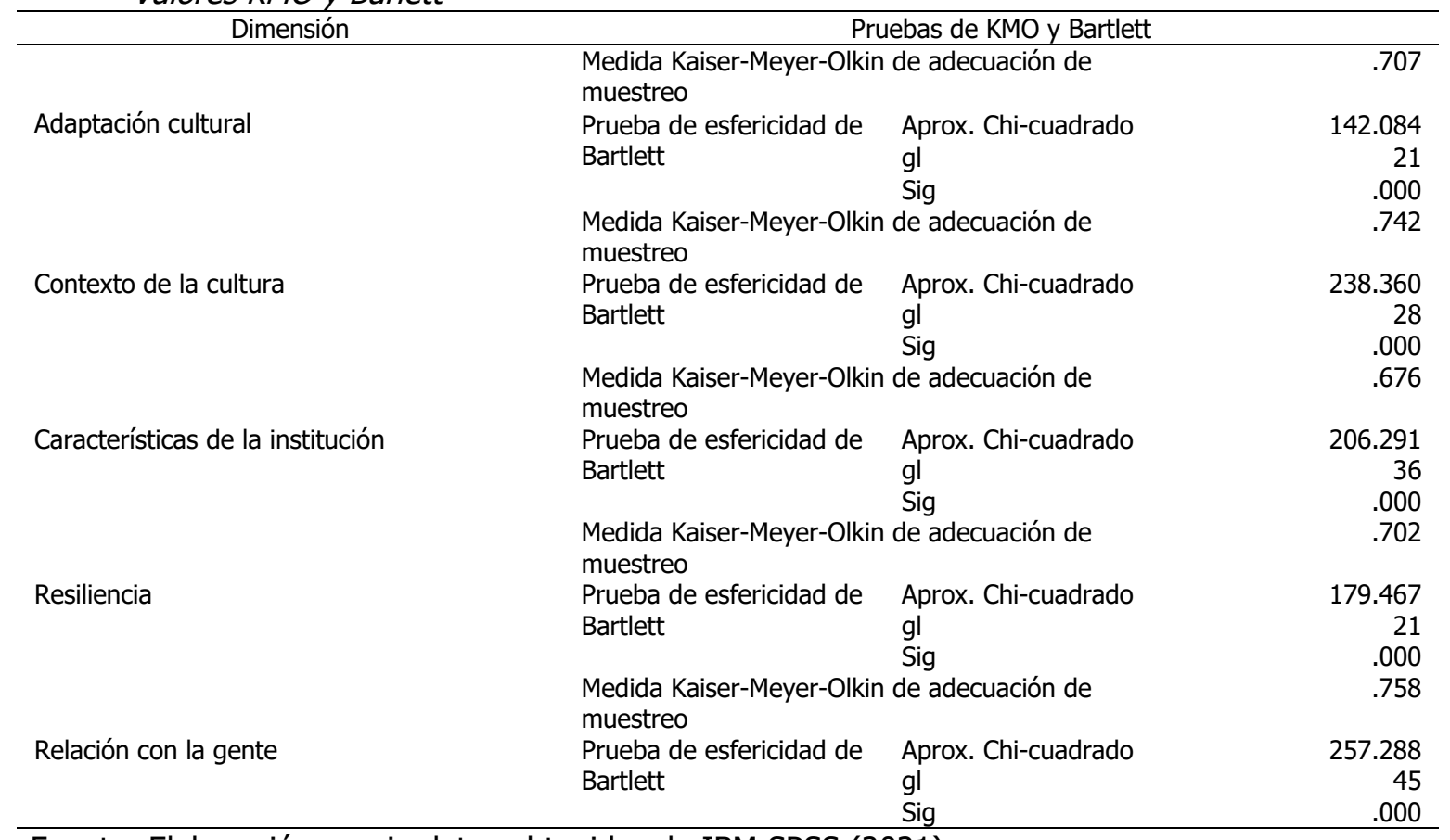

Fuente: Elaboración propia datos obtenidos de IBM SPSS (2021)

\section{Análisis factorial}

Para continuar con las pruebas de validación del instrumento, Pere y Anguiano-Carraso (2010) aseguran que el análisis factorial es un modelo estadístico que representa las relaciones entre un conjunto de variables que integran un instrumento. Asimismo, corresponde a encontrar de una forma exploratoria una estructura interna. Dicha estructura puede ser encontrada mediante dos formas. Primeramente, la creación de nuevos factores a partir de una variable. Seguido de, la reducción de dimensiones varimax. Es decir, eliminar aquellos ítems que muestren poca relevancia para la variable. Mientras que, por otro lado, 
el análisis factorial confirmatorio busca hasta que punto un conjunto de factores pueden ajustarse a los datos. Al mismo tiempo, es necesario establecer un nivel de confianza para aceptar o rechazar las hipótesis (Méndez y Rondón, 2012).

Para fines de esta investigación es utilizado el método de reducción de dimensiones, con la finalidad de eliminar aquellos ítems que muestren poca relevancia para la variable. Es decir, la prueba del índice de adecuación de la muestra individual (MSA) mide la correlación que tiene un ítem en específico con el resto. Asimismo, Cruz (2009) afirma que la matriz anti-imagen debe presentar una perfecta diagonal formada por valores por arriba de 0.60 . Hechas las consideraciones anteriores, la prueba MSA fue realizada en las cinco dimensiones arrojando resultados significativos para la reducción del instrumento.

Para la dimensión Adaptación cultural fueron realizadas las pruebas, en un primer análisis fueron eliminados los ítems AC4, el sistema se corrió nuevamente, arrojaron que los ítems AC2 y AC12 no cumplen con los valores mayores a 0.60 lo cual indicarían problemas de multicolinealidad. Finalmente, el análisis fue realizado nuevamente dando como resultado una perfecta diagonal con los valores mayores a .60 lo cual significa que los ítems suficiente colinealidad. La tabla 5 muestra los valores de MSA para la dimensión adaptación cultural.

\section{Tabla 5.}

Valores MSA para la dimensión adaptación cultural

\begin{tabular}{|c|c|c|c|c|c|c|c|c|}
\hline \multicolumn{9}{|c|}{ Matrices anti-imagen } \\
\hline & & Ítem 1 & Ítem 3 & Ítem 5 & Ítem 9 & Ítem 11 & Ítem 7 & Ítem 10 \\
\hline Covarianza & Ítem 1 & .803 & -.170 & .065 & -.090 & .089 & -.167 & -.133 \\
\hline \multirow[t]{8}{*}{ anti-imagen } & Ítem 3 & -.170 & .778 & -.152 & .098 & -.175 & -.007 & -.143 \\
\hline & Ítem 5 & .065 & -.152 & .904 & .042 & -.116 & -.057 & -.032 \\
\hline & Ítem 9 & -.090 & .098 & .042 & .819 & -.183 & -.179 & -.043 \\
\hline & Ítem & .089 & -.175 & -.116 & -.183 & .771 & -.118 & -.085 \\
\hline & 11 & & & & & & & \\
\hline & Ítem 7 & -.167 & -.007 & -.057 & -.179 & -.118 & .729 & -.155 \\
\hline & Ítem & -.133 & -.143 & -.032 & -.043 & -.085 & -.155 & .772 \\
\hline & 10 & & & & & & & \\
\hline Correlación & Ítem 1 & $.672^{a}$ & -.215 & .076 & -.111 & .113 & -.219 & -.169 \\
\hline \multirow[t]{8}{*}{ anti-imagen } & Ítem 3 & -.215 & $.666^{\mathrm{a}}$ & -.181 & .123 & -.226 & -.009 & -.184 \\
\hline & Ítem 5 & .076 & -.181 & $.686^{a}$ & .049 & -.139 & -.071 & -.039 \\
\hline & Ítem 9 & -.111 & .123 & .049 & $.665^{a}$ & -.230 & -.232 & -.054 \\
\hline & Ítem & .113 & -.226 & -.139 & -.230 & $.692^{a}$ & -.157 & -.110 \\
\hline & 11 & & & & & & & \\
\hline & Ítem 7 & -.219 & -.009 & -.071 & -.232 & -.157 & $.742^{\mathrm{a}}$ & -.206 \\
\hline & Ítem & -.169 & -.184 & -.039 & -.054 & -.110 & -.206 & $.785^{\mathrm{a}}$ \\
\hline & 10 & & & & & & & \\
\hline
\end{tabular}

a. Medidas de adecuación de muestreo (MSA)

Fuente: Elaboración propia datos obtenidos de IBM SPSS (2021) 
Para la dimensión contexto de la cultura fueron realizadas las pruebas de los valores MSA, donde se encontró que los ítems CC18 y CC13 contaban con valores por debajo de 0.60 por tal motivo procedieron a eliminarse. Finalmente, el análisis fue realizado nuevamente dando como resultado una diagonal con todos sus los valores por arriba a .60. La tabla 6 muestra los resultados de los valores MSA para la dimensión de contexto de la cultura.

Tabla 6.

Valores MSA para la dimensión contexto de la cultura

\begin{tabular}{|c|c|c|c|c|c|c|c|c|c|}
\hline \multicolumn{10}{|c|}{ Matrices anti-imagen } \\
\hline & & Ítem & Ítem & Ítem & Ítem & Ítem & Ítem & Ítem & Ítem \\
\hline & & 14 & 15 & 16 & 17 & 19 & 20 & 21 & 22 \\
\hline Covarianza & Ítem 14 & .697 & -.194 & .226 & -.062 & -.063 & .057 & -.100 & .024 \\
\hline \multirow[t]{7}{*}{ anti-imagen } & Ítem 15 & -.194 & .672 & -.063 & -.001 & .005 & -.076 & .043 & -.226 \\
\hline & Ítem 16 & -.226 & -.063 & .711 & -.004 & -.170 & -.039 & .126 & -.075 \\
\hline & Ítem 17 & -.062 & -.001 & -.004 & .825 & -.191 & -.084 & -.139 & .035 \\
\hline & Ítem 19 & -.063 & .005 & -.170 & -.191 & .733 & .006 & -.090 & -.096 \\
\hline & Ítem 20 & .057 & -.076 & -.039 & -.084 & .006 & .764 & -.162 & -.172 \\
\hline & Ítem 21 & -.100 & .043 & .126 & -.139 & -.090 & -.162 & .753 & -.149 \\
\hline & Ítem 22 & .024 & -.226 & -.075 & .035 & -.096 & -.162 & -.149 & .624 \\
\hline Correlación & Ítem 14 & $.724^{a}$ & -.284 & -.320 & -.082 & -.088 & .079 & -.138 & .037 \\
\hline \multirow[t]{7}{*}{ anti-imagen } & Ítem 15 & -.284 & $.744^{a}$ & -.090 & -.001 & .007 & -.106 & .060 & -.349 \\
\hline & Ítem 16 & -.320 & -.090 & $.718^{\mathrm{a}}$ & -.005 & -.236 & -.053 & .172 & -.113 \\
\hline & Ítem 17 & -.082 & -.001 & -.005 & $.757^{a}$ & -.246 & -.106 & -.176 & .049 \\
\hline & Ítem 19 & -.088 & .007 & -.236 & -.246 & $.786^{\mathrm{a}}$ & .008 & -.121 & -.142 \\
\hline & Ítem 20 & .079 & -.106 & -.053 & -.106 & .008 & $.774^{a}$ & -.213 & -.248 \\
\hline & Ítem 21 & -.138 & -.060 & .172 & -.176 & -.121 & -.212 & $.702^{\mathrm{a}}$ & -.217 \\
\hline & Ítem 22 & .037 & -.349 & -.113 & .049 & -.142 & -.248 & -.217 & $-743^{a}$ \\
\hline
\end{tabular}

Fuente: Elaboración propia datos obtenidos de IBM SPSS (2021)

Posteriormente, la dimensión característica de la institución en una primera prueba los ítems CI40, CI32 y CI46 mostraron valores no aceptados por lo cual fueron eliminados. Una segunda prueba fue realizada dando como resultado que los ítems CI33, CI36 y CI41 contaban con valores por debajo de 0.60 . Una tercera prueba fue realizando en esta ocasión únicamente los ítems CI39 y CI35 mostraron valores no aceptados. Finalmente, el análisis fue realizado nuevamente dando como resultado una diagonal con todos sus los valores por arriba a .60. La tabla 7 muestra los resultados de los valores MSA para la dimensión de características de la institución. 
Tabla 7.

Valores MSA para la dimensión características de la institución

\begin{tabular}{|c|c|c|c|c|c|c|c|c|c|c|}
\hline \multicolumn{11}{|c|}{ Matrices anti-imagen } \\
\hline & & Ítem & Ítem & Ítem & Ítem & Ítem & Ítem & Ítem & Ítem & Ítem \\
\hline & & 34 & 35 & 37 & 38 & 41 & 43 & 44 & 45 & 31 \\
\hline Covaria & Ítem & .764 & -.181 & .062 & -.067 & -.110 & .038 & -.059 & -.007 & -.176 \\
\hline nza & 34 & & & & & & & & & \\
\hline anti- & Ítem & -.181 & .724 & - & -.099 & -.088 & -.059 & .013 & -.152 & -.144 \\
\hline \multirow[t]{15}{*}{ imagen } & 35 & & & .073 & & & & & & \\
\hline & Ítem & .062 & -.073 & .843 & -.239 & -.076 & -.009 & -.066 & .017 & .017 \\
\hline & 37 & & & & & & & & & \\
\hline & Ítem & -.067 & -.099 & - & .792 & .016 & .087 & -.107 & .008 & -.086 \\
\hline & 38 & & & .239 & & & & & & \\
\hline & Ítem & -.110 & -.088 & - & .016 & .780 & .064 & -.223 & .173 & .010 \\
\hline & 41 & & & .076 & & & & & & \\
\hline & Ítem & .038 & -.059 & - & .087 & .064 & .726 & -.307 & -.077 & -.107 \\
\hline & 43 & & & .009 & & & & & & \\
\hline & Ítem & -.059 & .013 & - & -.107 & -.223 & -.307 & .631 & -.035 & -.002 \\
\hline & 44 & & & .066 & & & & & & \\
\hline & Ítem & -.007 & -.152 & .017 & .008 & .173 & -.077 & -.035 & .882 & -.002 \\
\hline & 45 & & & & & & & & & \\
\hline & Ítem & -.176 & -.144 & .017 & -.086 & .010 & -.107 & -.002 & -.070 & .781 \\
\hline & 31 & & & & & & & & & \\
\hline Correlac & Ítem & $.738^{a}$ & -.244 & .078 & -.087 & -.142 & .051 & -.085 & -.008 & -.228 \\
\hline ión anti- & 34 & & & & & & & & & \\
\hline \multirow[t]{16}{*}{ imagen } & Ítem & -.211 & $752^{\mathrm{a}}$ & - & -.131 & -.117 & -.085 & .020 & -.190 & -.191 \\
\hline & 35 & & & .092 & & & & & & \\
\hline & Ítem & .078 & -.093 & .676 & -.292 & -.094 & -.011 & -.090 & .020 & .021 \\
\hline & 37 & & & a & & & & & & \\
\hline & Ítem & -.087 & -.131 & - & $.694^{a}$ & .021 & .114 & -.152 & .010 & -.110 \\
\hline & 38 & & & .292 & & & & & & \\
\hline & Ítem & -.142 & -.117 & - & .021 & $.620^{\mathrm{a}}$ & .086 & -.318 & .209 & .012 \\
\hline & 41 & & & .094 & & & & & & \\
\hline & Ítem & .051 & -.082 & - & .114 & .086 & $.579^{a}$ & -.453 & -.096 & -.142 \\
\hline & 43 & & & .011 & & & & & & \\
\hline & Ítem & -.085 & .020 & - & -.152 & -.318 & -.453 & $.629^{a}$ & -.047 & -.003 \\
\hline & 44 & & & .090 & & & & & & \\
\hline & Ítem & -.008 & -.190 & .020 & .010 & .209 & -.096 & -.047 & $.601^{a}$ & -.084 \\
\hline & 45 & & & & & & & & & \\
\hline & Ítem & -.228 & -.191 & .021 & -.110 & .012 & -.142 & -.003 & -.084 & $.768^{\mathrm{a}}$ \\
\hline & 31 & & & & & & & & & \\
\hline
\end{tabular}

a. Medidas de adecuación de muestreo (MSA)

Fuente: Elaboración propia datos obtenidos de IBM SPSS (2021) 
Posteriormente, en la dimensión resiliencia fueron realizadas las pruebas de análisis donde se detectaron que los ítems R51 y R54 mostraron menores a .06 por lo cual fueron eliminados. El análisis se volvió a realizar dando como resultado que los ítems R60, R67 y R58 indicaban problemas de multicolinealidad. Finalmente, un nuevo análisis fue realizado dando como resultado una diagonal perfecta con todos sus los valores por arriba a .60. La tabla 8 muestra los resultados de los valores MSA para la dimensión de resiliencia.

Tabla 8.

Valores MSA para la dimensión resiliencia

\begin{tabular}{|c|c|c|c|c|c|c|c|c|}
\hline \multicolumn{9}{|c|}{ Matrices anti-imagen } \\
\hline \multirow{12}{*}{$\begin{array}{l}\text { Covarianza } \\
\text { anti-imagen }\end{array}$} & & Ítem 48 & Ítem 50 & Ítem 55 & Ítem 56 & Ítem 59 & Ítem 62 & Ítem 66 \\
\hline & Ítem & .690 & -.012 & -.171 & -.176 & .036 & -.005 & -.192 \\
\hline & Ítem & -.012 & .784 & .028 & -.028 & -.188 & .066 & -.268 \\
\hline & 50 & & & & & & & \\
\hline & Ítem & -.171 & .028 & .700 & -.226 & .014 & -.118 & -.009 \\
\hline & 55 & & & & & & & \\
\hline & Ítem & -.174 & -.028 & -.226 & .647 & -.161 & -.052 & -.026 \\
\hline & $\begin{array}{l}56 \\
\text { Ítem }\end{array}$ & .036 & -188 & 014 & -161 & .811 & - 179 & -013 \\
\hline & 59 & & & & & & & \\
\hline & Ítem & -.005 & .066 & -.118 & -.052 & -.179 & .883 & -.024 \\
\hline & 62 & & & & & & & \\
\hline & $\begin{array}{l}\text { Ítem } \\
66\end{array}$ & -.192 & -.268 & -.009 & -.026 & -.013 & -.024 & .745 \\
\hline \multirow{7}{*}{$\begin{array}{l}\text { Correlación } \\
\text { anti-imagen }\end{array}$} & $\begin{array}{l}\text { Ítem } \\
48\end{array}$ & $.734^{\mathrm{a}}$ & -.017 & -.246 & -.260 & .048 & -.006 & -.267 \\
\hline & $\begin{array}{l}\text { Ítem } \\
50\end{array}$ & -.017 & $.618^{\mathrm{a}}$ & .037 & -.040 & -.236 & .080 & -.350 \\
\hline & $\begin{array}{l}\text { Ítem } \\
55\end{array}$ & -.246 & .037 & $.724^{\mathrm{a}}$ & -.336 & .018 & -.150 & -.012 \\
\hline & $\begin{array}{l}\text { Ítem } \\
56\end{array}$ & -.260 & -.040 & -.336 & $.733^{a}$ & -.222 & -.069 & -.037 \\
\hline & $\begin{array}{l}\text { Ítem } \\
59\end{array}$ & .048 & -.236 & .018 & -.222 & $.665^{\mathrm{a}}$ & -.211 & -.016 \\
\hline & $\begin{array}{l}\text { Ítem } \\
62\end{array}$ & -.006 & .080 & -.150 & -.069 & -.211 & $.716^{a}$ & -.030 \\
\hline & $\begin{array}{l}\text { Ítem } \\
66 \\
\text { ecuació }\end{array}$ & $\begin{array}{r}-.267 \\
\text { nuestreo }\end{array}$ & -.350 & -.012 & -.037 & -.016 & -.030 & $.679^{a}$ \\
\hline
\end{tabular}

Fuente: Elaboración propia datos obtenidos de IBM SPSS (2021)

Posteriormente, en la dimensión relación con la gente presentó en un primer análisis valores por debajo de .60 por tal motivo el ítem RG69 fue eliminado El análisis se volvió a realizar dando como resultado una diagonal perfecta con todos sus los valores por arriba a .60. La tabla 9 muestra los resultados de los valores MSA para la dimensión relación con la gente. 
Tabla 9.

Valores MSA para la dimensión relación con la gente

\begin{tabular}{|c|c|c|c|c|c|c|c|c|c|c|c|}
\hline \multicolumn{12}{|c|}{ Matrices anti-imagen } \\
\hline \multirow{22}{*}{$\begin{array}{l}\text { Covarian } \\
\text { za anti- } \\
\text { imagen }\end{array}$} & & Ítem & İtem & Ítem & Ítem & Ítem & İtem & İtem & Ítem & Ítem & Ítem \\
\hline & & 70 & 71 & 72 & 73 & 75 & 78 & 79 & 80 & 81 & 82 \\
\hline & Ítem & .699 & - & - & -.094 & - & - & -.194 & - & - & .115 \\
\hline & 70 & & .057 & .043 & & .106 & .053 & & .026 & .027 & \\
\hline & Ítem & - & .871 & .012 & -.200 & - & .001 & .010 & - & - & .042 \\
\hline & 71 & .057 & & & & .007 & & & .131 & .029 & \\
\hline & Ítem & - & .012 & .665 & -.039 & - & .003 & -.106 & - & .038 & - \\
\hline & 72 & .043 & & & & .262 & & & .031 & & .056 \\
\hline & Ítem & - & - & - & .781 & - & - & -.036 & - & - & - \\
\hline & 73 & .094 & .200 & .039 & & .086 & .005 & & .059 & .081 & .076 \\
\hline & Ítem & - & - & - & -.086 & .640 & - & -.057 & - & .058 & - \\
\hline & 75 & .106 & .007 & .262 & & & .014 & & .031 & & .055 \\
\hline & Ítem & - & .001 & .003 & -.005 & - & .775 & -.202 & .008 & - & - \\
\hline & 78 & .053 & & & & .014 & & & & .135 & .191 \\
\hline & Ítem & - & .010 & - & -.036 & - & - & .611 & - & .033 & .055 \\
\hline & 79 & .194 & & .106 & & .057 & .202 & & .138 & & \\
\hline & Ítem & - & - & - & -.059 & - & .008 & -.138 & .785 & .052 & - \\
\hline & 80 & .026 & .131 & .031 & & .031 & & & & & .178 \\
\hline & Ítem & .027 & .029 & .038 & -.081 & .058 & - & .033 & .052 & .949 & .021 \\
\hline & 81 & & & & & & .135 & & & & \\
\hline & Ítem & .115 & .042 & - & -.076 & - & & .055 & - & .021 & .840 \\
\hline & 82 & & & .056 & & .055 & .191 & & .178 & & \\
\hline \multirow{20}{*}{$\begin{array}{l}\text { Correlaci } \\
\text { ón anti- } \\
\text { imagen }\end{array}$} & Ítem & .797 & - & - & -.127 & - & - & -.296 & - & - & .150 \\
\hline & 70 & $a$ & .073 & .063 & & .158 & .072 & & .035 & .033 & \\
\hline & Ítem & - & .715 & .015 & -.243 & - & .001 & .013 & - & & .049 \\
\hline & 71 & .073 & $\mathrm{a}$ & & & .009 & & & .158 & .032 & \\
\hline & Ítem & - & .015 & .777 & -.054 & - & .004 & -.166 & - & .048 & - \\
\hline & 72 & .063 & & a & & .401 & & & .042 & & .074 \\
\hline & Ítem & - & - & - & $.810^{a}$ & - & - & -.052 & - & - & - \\
\hline & 73 & .127 & .243 & .054 & & .121 & .007 & & .075 & .094 & .094 \\
\hline & Ítem & - & - & - & -.121 & .779 & - & -.091 & - & .075 & - \\
\hline & 75 & .158 & .009 & .401 & & $a$ & .020 & & .044 & & .075 \\
\hline & Ítem & - & .001 & .004 & -.007 & - & .709 & -.293 & .010 & - & - \\
\hline & 78 & .072 & & & & .020 & $a$ & & & .158 & .237 \\
\hline & Ítem & - & .013 & - & -.052 & - & - & $.768^{a}$ & - & .044 & .077 \\
\hline & 79 & .296 & & .166 & & .091 & .293 & & 199 & & \\
\hline & Ítem & - & - & - & -.076 & - & .010 & -.199 & .793 & .060 & - \\
\hline & 80 & .035 & .158 & .042 & & .044 & & & $a$ & & .219 \\
\hline & Ítem & - & - & .048 & -.094 & .075 & - & .044 & .060 & .452 & - \\
\hline & 81 & .033 & .032 & & & & .158 & & & $a$ & .023 \\
\hline & Ítem & .150 & .049 & - & -.094 & - & - & .077 & - & .023 & .585 \\
\hline & $\begin{array}{c}82 \\
\text { adecu }\end{array}$ & 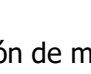 & 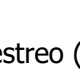 & A) & & .075 & .237 & & .210 & & a \\
\hline
\end{tabular}

Fuente: Elaboración propia datos obtenidos de IBM SPSS (2021)

Adicionalmente, fue realizada la prueba de comunalidades con la finalidad de conocer la varianza que presentan las variables. En tal sentido, las comunalidades son la contabilización por estructura de un factor. Al mismo tiempo, requieren explicar la mitad de varianza de cada variable. Por tal motivo, los valores deben de estar por arriba de 0.50 (Cruz, 2009). La tabla 10 muestra las comunalidades de las dimensiones de esta investigación. Donde puede observarse que cada dimensión cuenta con ítems con los valores aceptados. 
Tabla 10.

Comunalidades

\begin{tabular}{|c|c|c|c|c|c|}
\hline Ítem & $\begin{array}{c}\text { Adaptación } \\
\text { cultural }\end{array}$ & $\begin{array}{c}\text { Contexto de la } \\
\text { cultura }\end{array}$ & $\begin{array}{c}\text { Características de } \\
\text { la institución }\end{array}$ & Resiliencia & $\begin{array}{c}\text { Relación con la } \\
\text { gente }\end{array}$ \\
\hline İtem 1 & .722 & - & - & - & - \\
\hline Ítem 2 & .665 & - & - & - & - \\
\hline İtem 5 & .646 & - & - & - & - \\
\hline İtem 9 & .744 & - & - & - & - \\
\hline Ítem 11 & .643 & - & - & - & - \\
\hline Ítem 7 & .573 & - & - & - & - \\
\hline Ítem 10 & .512 & - & - & - & - \\
\hline Ítem 14 & - & .597 & - & - & - \\
\hline Ítem 15 & - & .656 & - & - & - \\
\hline Ítem 16 & - & .654 & - & - & - \\
\hline Ítem 17 & - & .694 & - & - & - \\
\hline Ítem 19 & - & .585 & - & - & - \\
\hline Ítem 20 & - & .620 & - & - & - \\
\hline Ítem 21 & - & .618 & - & - & - \\
\hline Ítem 22 & - & .681 & - & - & - \\
\hline Ítem 34 & - & - & .675 & - & - \\
\hline Ítem 35 & - & - & .574 & - & - \\
\hline Ítem 37 & - & - & .734 & - & - \\
\hline Ítem 38 & - & - & .650 & - & - \\
\hline Ítem 41 & - & - & .690 & - & - \\
\hline Ítem 43 & - & - & .778 & - & - \\
\hline İtem 44 & - & - & .751 & - & - \\
\hline Ítem 45 & - & - & .666 & - & - \\
\hline Ítem 31 & - & - & .535 & - & - \\
\hline İtem 48 & - & - & - & .682 & - \\
\hline Ítem 50 & - & - & - & .738 & - \\
\hline Ítem 55 & - & - & - & .671 & - \\
\hline Ítem 56 & - & - & - & .620 & - \\
\hline Ítem 59 & - & - & - & .720 & . \\
\hline Ítem 62 & - & - & - & .633 & - \\
\hline Ítem 66 & - & - & - & .648 & - \\
\hline Ítem 70 & - & - & - & - & .628 \\
\hline İtem 71 & - & - & - & - & .724 \\
\hline Ítem 72 & - & - & - & - & .573 \\
\hline Ítem 73 & - & - & - & - & .536 \\
\hline Ítem 75 & - & - & - & - & .586 \\
\hline Ítem 78 & - & - & - & - & .664 \\
\hline İtem 79 & - & - & - & - & .617 \\
\hline Ítem 80 & - & - & - & - & .501 \\
\hline Ítem 81 & - & - & - & - & .709 \\
\hline Ítem 82 & - & - & - & - & .805 \\
\hline
\end{tabular}

Fuente: Elaboración propia datos obtenidos de IBM SPSS (2021)

Finalmente, la varianza total explicada es la suma de la varianza común, la varianza específica y la varianza de error aleatorio. Al mismo tiempo, la varianza exige un valor mayor al 50\% para considerarse aceptada (García, Mateos y Rom-Pérez, 2017). Por otra parte, la varianza total explicada arroja el número de componentes que conforman la variable, a través, del criterio de rotación Varimax. De acuerdo con, Courville y Thompson (2001) aseguran que el método Varimax es la rotación cuando no existe un factor dominante. Es decir, busca maximizar las ponderaciones a nivel del factor. Por tal motivo, es la capacidad que tiene un ítem para ser representativo.

Con respecto a la varianza el instrumento muestra un $75 \%$ de varianza total explicada lo cual es suficiente para considerar una estructura factorial consistente que apoya la validez 
de cada constructo. Por una parte, la tabla 11 muestra la varianza total explicada del instrumento, mientras que, la tabla 12 muestra la matriz de componente rotado de las dimensiones.

Tabla 11.

Varianza total explicada

\begin{tabular}{|c|c|c|c|c|c|c|c|c|c|}
\hline \multicolumn{10}{|c|}{ Varianza total explicada } \\
\hline \multicolumn{4}{|c|}{ Autovalores iniciales } & \multicolumn{3}{|c|}{$\begin{array}{c}\text { Sumas de cargas al cuadrado de } \\
\text { la extracción }\end{array}$} & \multicolumn{3}{|c|}{$\begin{array}{c}\text { Sumas de cargas al cuadrado de } \\
\text { la rotación }\end{array}$} \\
\hline Componente & Total & $\begin{array}{c}\% \text { de } \\
\text { varianza }\end{array}$ & $\begin{array}{c}\% \\
\text { acumulado }\end{array}$ & Total & $\begin{array}{c}\% \text { de } \\
\text { varianza }\end{array}$ & $\begin{array}{c}\% \\
\text { acumulado }\end{array}$ & Total & $\begin{array}{c}\% \text { de } \\
\text { varianza }\end{array}$ & $\begin{array}{c}\% \\
\text { acumulado }\end{array}$ \\
\hline 1 & 2.755 & 55.097 & 55.097 & 2.755 & 55.097 & 55.097 & 2.145 & 42.899 & 42.899 \\
\hline 2 & 1.025 & 20.495 & 75.595 & 1.025 & 20.495 & 75.592 & 1.635 & 32.693 & 75.592 \\
\hline 3 & .451 & 9.022 & 84.613 & & & & & & \\
\hline 4 & .399 & 7.974 & 92.587 & & & & & & \\
\hline 5 & .371 & 7.413 & 100.000 & & & & & & \\
\hline
\end{tabular}

Fuente: Elaboración propia datos obtenidos de IBM SPSS (2021)

Tabla 12.

Matriz de componente rotado

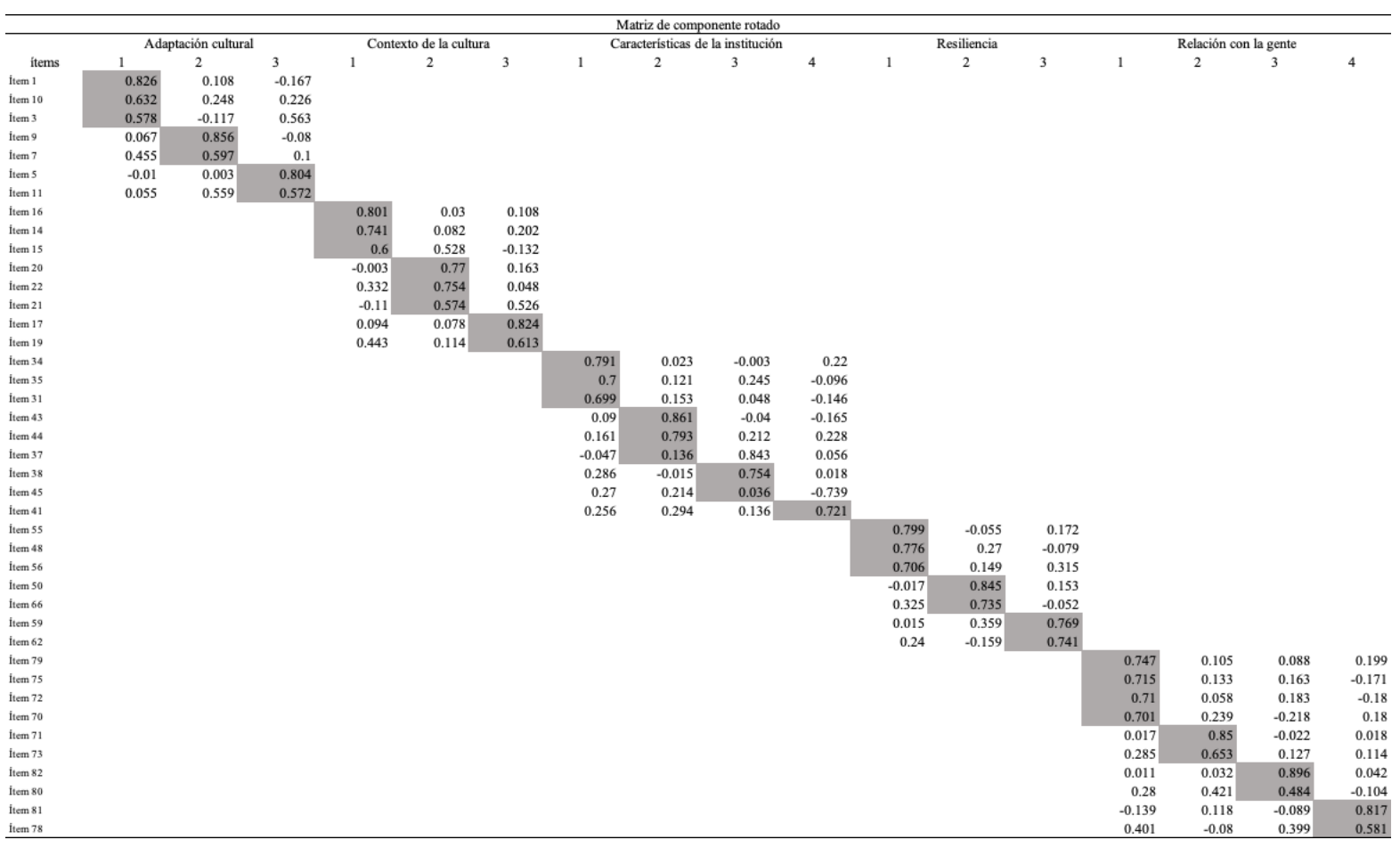

Fuente: Elaboración propia datos obtenidos de IBM SPSS (2021)

Los resultados de esta investigación se dividen entre los ítems significativos de cada una de las dimensiones y la reducción que se logró obtener en cada una de ellas.

En cuanto a los ítems significativos, las dimensiones encontradas en nuestro estudio para explicarla son: 
Dimensión 1 Adaptación cultural: explica tras la rotación una varianza del 64\% la mayor parte recogida en cuatro componentes. Donde todos sus valores salieron positivos. Identificamos que esta dimensión el componente uno lo integran los ítems I1, I10, E I3. El componente dos lo conforman los ítems I9 y I7. Finalmente, el componente cuatro por los ítems I5 y I11.

Dimensión 2 Contexto de la cultura: explica una varianza del 63\%. Por lo tanto, esta dimensión quedó integrada por cuatro componentes. Donde el componente uno el componente uno está conformado por I16, I14, I15. El componente dos por I20, I22, I21. Finalmente, el componente tres lo integran los ítems I17 y I19.

Dimensión 3 Características de la institución: la varianza presentó un $67 \%$ de varianza. En tal sentido, el constructo Características de la institución quedó conformado por cuatro componentes. Para el componente uno los ítems que lo conforman son I34, I35 y I31. El segundo componente está integrado por los ítems I43, I44. Posteriormente, el componente tres lo forman los ítems I37, I38 y I45. Finalmente, el componente cuatro quedó integrado por el ítem I41.

Dimensión 4 resiliencia: la varianza mostró valores de 67\% de varianza. Al mismo tiempo, el constructo quedó conformado por tres componentes. Es decir, el componente uno lo integran los ítems I55, I48 y I56. Por su parte, el componente dos está constituido por los ítems I50 y I66. Finalmente, el componente tres lo conforman los ítems I59 y I62.

Dimensión 5 relación con la gente: la varianza presentó valores de $63 \%$ de varianza. Al mismo tiempo, el constructo quedó conformado por cuatro componentes. Es decir, el componente uno lo integran los ítems I79, I75, I72 e I70. Por su parte, el componente dos está constituido por los ítems I71 e I73. Por otra parte, el componente tres lo conforman los ítems I82 y I80. Finalmente, el componente cuatro quedó integrado por los ítems I81 y I78.

Adicionalmente, la tabla 13 muestra en resumen los estadísticos descriptivos obtenidos de las cinco dimensiones. Asimismo, puede observarse resultados homogéneos entre la media y desviación estándar que componen el instrumento de investigación.

Tabla 13.

Estadísticos descriptivos

\begin{tabular}{lccccc}
\hline \multicolumn{1}{c}{ Dimensión } & $\mathrm{N}$ & Mínimo & Máximo & Media & Desv. Desviación \\
\hline Adaptación cultural & 158 & 2.70 & 5.00 & 4.2101 & .47299 \\
Contexto de la cultura & 158 & 1.60 & 5.00 & 3.3949 & .60715 \\
Características de la & 158 & 3.13 & 5.00 & 4.3758 & .42943 \\
institución & 158 & 2.17 & 5.00 & 4.1514 & .44742 \\
Resiliencia & 158 & 2.75 & 5.00 & 4.2869 & .36055 \\
Relación con la gente & &
\end{tabular}

Fuente: Elaboración propia datos obtenidos de IBM SPSS (2021) 
Para finalizar, la tabla 14 muestra la clasificación de los ítems con las cinco dimensiones de estudio.

Tabla 14.

Agrupación de los ítems por dimensiones

\begin{tabular}{ccccc}
\hline Dim. 1 & Dim. 2 & Dim. 3 & Dim. 4 & Dim. 5 \\
\hline I1 & I16 & I34 & I55 & I79 \\
I10 & I14 & I35 & I48 & I75 \\
I13 & I15 & I31 & I56 & I72 \\
I9 & I20 & I43 & I50 & I70 \\
I17 & I22 & I44 & I66 & I71 \\
I5 & I21 & I37 & I59 & I73 \\
I11 & I138 & I62 & I82 \\
& I19 & 45 & & I80 \\
& & I41 & & I 81 \\
\hline
\end{tabular}

Fuente: Elaboración propia datos obtenidos de IBM SPSS (2021)

\section{Discusiones y conclusiones}

El objetivo de esta investigación ha sido establecer un instrumento de medición sobre los factores que facilitan el proceso de aculturación por el que atraviesan estudiantes de educación superior durante su intercambio académico al extranjero. Su desarrollo permitirá llevar a cabo investigaciones y estudios para lograr adecuar este instrumento de acuerdo a las necesidades de los estudiantes. Al mismo tiempo, ofrecer cursos de orientación cultural a aquellos alumnos próximos a realizar una movilidad. Con la finalidad de que, presenten un buen rendimiento académico.

Lo primero que podemos observar es un agrupamiento próximo al presentado en los instrumentos de Oses (2014) y Peralta, Ramírez y Castaño (2006). Esto debido a que recogía diversas dimensiones conformadas por 15 y 19 ítems, respectivamente. Los resultados de esta investigación mostraron únicamente cinco dimensiones agrupados por un promedio de 8 a 11 ítems.

En segundo lugar, hemos de admitir una diferencia en el grado de varianza debido a que en esta investigación existen dos dimensiones que comparten el mismo nivel (67\%). Es decir, la dimensión característica de la institución y resiliencia arrojan el mayor número de componentes. Sin embargo, como señala Castello y Osborne (2005) las diferencias entre instrumentos varían en función del área geográfica y tipo de muestra a la que son aplicados.

En resumen, el instrumento presenta una estructura factorial consistente integrada por ítems que miden exactamente lo que se deben de medir las variables de esta investigación. 
Por tal motivo, el instrumento cuenta con suficiente evidencia empírica que aporte a la medición de los factores que facilitan el proceso de aculturación en estudiantes que realizan un intercambio académico al extranjero. En general, todos los datos muestran consistencia para las variables, lo que probablemente indique que la adaptación cultural, el contexto cultural, las características de la institución, la resiliencia y la relación con la gente son factores que sí los estudiantes los aplican y cuentan con conocimientos previos estos benefician a su proceso de aculturación y por ende presentarán mejor rendimiento académico durante su movilidad.

Finalmente, para futuras investigaciones se busca estudiar entre los estudiantes que aplicaron estos factores y los estudiantes que no contaron con esta información. Al mismo tiempo, identificar las zonas geográficas donde los estudiantes consideran fue mejor la aplicación de los estudiantes y percibir el grado de aculturación de estos, así como determinar el impacto del factor económico en la movilidad, es decir, determinar diferencias culturales con base a la economía y desarrollo del país de acuerdo con el lugar de procedencia y el lugar destino para la movilidad académica.

\section{Referencias}

Aguilar, S.L., Gallegos, A., y Muñiz, S. (2019). Análisis de los componentes y definición del concepto de resiliencia: una revisión narrativa. Revista de Investigación Psicológica, (22), 77-100.

Ang, S., Van Dyne, L., \& Koh. (2004). The measurement of cultural intelligence. Academy of Management Meetings Symposium on Cultural Intelligence in the 21st Century.

Arenas, P., y Urzúa, A. (2016). Estrategias de aculturación e identidad étnica: un estudio en migrantes sur-sur en el norte de Chile. Universitas Psychologica, 15(1), 15-25. https://doi.org/10.11144/Javeriana.upsy15-1.eaie

Arends-Tóth, J. y Van de Vijver, F. J. R. (2007). Acculturation attitudes: A comparison of measurement methods. Journal of Applied Social Psychology, 377), 1462-148. https://doi.org/10.1111/j.1559-1816.2007.00222.x

Bartolomé, M., Cabrera, F., Espín, J. V., del Campo, J., Marín, M. A., Rodríguez, M., Sandín, M. P. y Sabariego, M. (2005). La construcción de la identidad en contextos multiculturales. CIDE. MADRID.

Beaven, A. M. G. (2012). An exploration of Cross-Cultural Adaptation in the Contexto of European Student Mobility. [Tesis doctoral, University of Warwick. Londres]. 
Berry, J., Phinney, J., Sam, D., y Vedder, P. (2006). Inmigrant Youth: Acculturation, Identity, and Adaptation. Applied Psychology: An International Review, 55(3), 303-332. https://doi.org/10.111/j.1464-0597.2006.x

Borboa, E. y Delhumeau, S. (2016). Validez de contenido de un instrumento para medir la responsabilidad social de las empresas bancarias. RECAI Revista de Estudios En Contaduría, Administración e Informática, 5(12), 1-29. https://recai.uaemex.mx/article/view/8927/7526

Cadena, P., Rendón, R., Aguilar, J., Salinas, E., De la Cruz, F., y Sangerman, D. (2017). Métodos cuantitativos, métodos cualitativos o su combinación en la investigación: un acercamiento en las ciencias sociales. Revista Mexicana de Ciencias Agrícolas, 8(7), 1603-1617.

Castro, A. (2011). Estrategias de aculturación y adaptación psicológica y sociocultural de estudiantes extranjeros en la Argentina. Interdisciplinaria, 28(1), 115-130. https://www.redalyc.org/pdf/180/18022327007.pdf

Church, A. (1982). Sojourner adjustment. Psychological Bulletin, 91(3), 540-572.

Cohen, R. y Swerdlick, M. (2001). Pruebas y Evaluación Psicológicas. Introducción a las Pruebas y a la Medición. Ciudad de México: McGraw Hill.

Costello, A. B. y Osborne, J. (2005). Best practices in exploratory factor analysis: four recommendations for getting the most from your analysis. Practical Assessment Research and Evaluation, 10(7), 1-9. https://www.researchgate.net/publication/209835856_Best_Practices_in_Explorato ry_Factor_Analysis_Four_Recommendations_for_Getting_the_Most_From_Your_An alysis

Courville, T. y Thompson, B. (2001). Use of structure coefficients in published multiple regression articles: Beta is not enough. Education Psychological Measurement, (61), 229-248.

Cruz, R. (2009). Innovación en servicios de telecomunicaciones a través de la gestión del conocimiento. [Tesis doctoral, Universidad Autónoma de Nuevo León]. http://eprints.uanl.mx/11825/1/A8.pdf

Escobar, J. y Cuervo, A. (2008). Validez de contenido y juicio de expertos: una aproximación a su utilización. Avances en medición. (6), 27-36.

Ferrando, P. J., y Anguiano-Carrasco, C. (2010). El análisis factorial como técnica de investigación en psicología. Papeles del Psicólogo, 31(1), 18-33. https://www.redalyc.org/pdf/778/77812441003.pdf 
Ferrer, R., Palacio, J., Hoyos, O., y Madariaga, C. (2014). Proceso de aculturación y adaptación del inmigrante: características individuales y redes sociales. Psicología $\begin{array}{lll}\text { desde } \quad \text { el } & \text { 31(3), }\end{array}$ https://www.redalyc.org/pdf/213/21332837009.pdf

Fiocchi, M.C. y Rojas, H. (2015). La experiencia de intercambio estudiantil en el extranjero: Análisis de las percepciones de chilenos que en su adolescencia participaron en programas de youth for understanding. Última década, 23(43), 207-233. https://dx.doi.org/10.4067/SO718-22362015000200008

Folivoc, C.J. (2009). Commentary: On the wisdom and challenges of culturally attuned treatments for Latinos. Journal of Consulting and Clinical Psychology, 774), 751762. https://www.redalyc.org/pdf/560/56041784007.pdf

García, F., Alfaro, A., Hernández, A. y Molina, M. (2006). Diseño de Cuestionarios para la recogida de información: metodología y limitaciones. Revista Clínica de Medicina de Familia, 1(5), 232-236. https://www.redalyc.org/pdf/1696/169617616006.pdf

García, J.A., García del Castillo, A., López, C., Dias, P.C. (2016). Conceptualización teórica de la resiliencia psicosocial y su relación con la salud. Salud y drogas, 16(1), 59-68.

García, B., Mateos, A., y Romo-Pérez, V. (2017). Construcción y validación de un instrumento para identificar las percepciones de los docentes de Ciencias sobre el modelo de enseñanza por competencias. Estudios Pedagógicos, XLII(1), 139-156.

González, Z., Mijares, B. (2018). Concepto de resiliencia: desde la diferenciación de otros constructos, escuelas y enfoques. Revista Científica Electrónica de Ciencias Humanas, (39), 30-43.

Granada, H. (2003). La cultura como estrategia de adaptación en la interacción sujeto social ambiente. Investigación \& Desarrollo, 11(1), 134-161. https://www.redalyc.org/pdf/268/26811106.pdf

Granados, L.F., Alvarado, S.V. y Carmona, J. (2017). El camino a la resiliencia: del sujeto individual al sujeto político. Magis. Revista Internacional de Investigación en Educación, 10(20), 49-68

Guzman, E. y Burke, M. (2003). Development and test of an international student performance taxonomy. International Journal of Intercultural Relations, 276), 659https://dx.doi.org/10.1016/j.ijintrel.2003.08.006

Hair, J. F., Anderson, R. E., Tatham, R. L., y Black, W. C. (2005). Multivariate data analysis. Nueva York: Prentice All International.

Hendrix, K. (2015). La aculturación, identidad y adaptación de los adolescentes inmigrantes 
del colegio NT2 Mundium. [Tesis de maestría, Universidad de Utrecht].

Hernández, J.A.R., Hernández, G.T., y González, Á. (2011). Acculturative stress in LatinAmerican immigrants: An assesment proposal. The Spanish Journal of Psychology, 14(1), 227-236. https://www.redalyc.org/pdf/172/17217456020.pdf

Jiménez, A. (2015). La movilidad estudiantil y el intercambio académico en la ENEO UNAM. Una estrategia hacia la consolidación de Enfermería. Enfermería Universitaria, 12(1), 1-2. https://www. redalyc.org/pdf/3587/358741842001.pdf

Levy, J. P., y Varela, J. (2003). Multivariate Analysis for Social Science. (D. Fayerman, Ed.) Madrid: Pearson.

Lupano, M.L. y Castro, A. (2013). Predictores de adaptación psicológica y académica de estudiantes universitarios extranjeros en Argentina. Interamerican Journal of Psychology, 48(3), 328-337. https://www.redalyc.org/pdf/284/28437897009.pdf

Méndez, C. y Rondón, M. A. (2012). Introducción al análisis factorial exploratorio. Revista Colombiana de Psiquiatría, 41(1), 197-207. https://www.redalyc.org/pdf/806/80624093014.pdf

Minjárez, M. (2012). La influencia de la aculturación en las estrategias de integración sociocultural y académica de los estudios transnacionales de retorno en la Universidad de Sonora. [Tesis de maestría, Universidad de Sonora]. https://pics.unison.mx/maestria/wp-content/uploads/2018/01/Minjares-Soza-Tesismaestria.pdf

Navas, M., Pumares, P., Sánchez, J., García, M. C., Rojas, A., Cuadrado, I., Asensio, M., y Fernández, J. (2004). Estrategias y actitudes de aculturación: la perspectiva de los inmigrantes $y$ de los autóctonos en Almería. Universidad de Almería. https://www.researchgate.net/profile/Isabel_Cuadrado_Guirado/publication/29279 9964_Las_actitudes_de_aculturacion_de_autoctonos_e_inmigrantes_en_Almeria_a _traves_del_modelo_ampliado_de_aculturacion_relativa/links/5a1d3f780f7e9b2a53 170c4e/Las-actitudes-de-aculturacion-de-autoctonos-e-inmigrantes-en-Almeria-atraves-del-modelo-ampliado-de-aculturacion-relativa.pdf

Oses, P. (2014). Análisis de los factores que facilitan o dificultan a adaptación de los estudiantes de intercambio en la Facultad de Economía y Negocios de la Universidad de Chile. [Tesis de pregrado, Universidad de Chile]. http://repositorio.uchile.cl/bitstream/handle/2250/115363/Seminario\%20de\%20Tit ulo\%20-\%20Paulina\%200ses.pdf?sequence=1\&isAllowed=y

Padoan, S.G. (2017). Choque y adaptación sociocultural una visión en espejo: vascos y brasileños.

Universitas

Psychologica, $16(5)$. 
http://www.scielo.org.co/pdf/rups/v16s5/1657-9267-rups-16-s5-00105.pdf

Páez, D., Gonzalez, J. L., Aguilera, N., y Zubieta, E. (2000). Identidad cultural, aculturación y adaptación de los inmigrantes latinoamericanos (chilenos) en el País Vasco. Chile: Centro Cultural Chileno.

Paz, M. (2017). El proceso de adaptación sociocultural: un modelo sociocognitivo de aculturación. [Tesis doctoral, Universidad Pontificia Comillas].

Peralta, S., Ramírez, A. y Castaño, H. (2006). Factores resilientes asociados al rendimiento académico en estudiantes pertenecientes a la Universidad de Sucre (Colombia). Psicología desde el Caribe, (17), 196-219. https://www.redalyc.org/pdf/213/21301709.pdf

Pere, F. y Anguiano-Carroso, C. (2010). El análisis factorial como técnica de investigación en psicología. Papeles del Psicólogo, 31(1), 18-33. https://www.redalyc.org/pdf/778/77812441003.pdf

Pozzo, M.I. (2012). Pluralismo cultural y educación: el caso canadiense. Revista de Educación, 28(2), 257-284. https://www.scielo.br/pdf/edur/v28n2/a12v28n2.pdf

Searle, J. (1990). Collective intentions and actions. Intentions in communication, 401, 401414. https://doi.org./10.2307/40041290

Tomasello, M., Kruher, A. y Ratner, H. (1993). Cultural learning. Behavioral and Brain Sciences, (16), 495-552. https://www.cambridge.org/core/journals/behavioral-andbrain-sciences/article/abs/culturallearning/C1CB7EA0CF7D53D14AA31633D7AF82BF

Ward, C., Bochner, S., y Furnham, A, (2001). The Psychology of culture shock. Nueva York: Routledge. 